\title{
The reproductive season of scleractinian corals in Socotra,
}

\section{Yemen [version 1; peer review: 2 approved]}

\author{
Andrew H. Baird (D1, David Abrego2, Emily J. Howells³, Vivian R. Cumbo1 \\ ${ }^{1}$ ARC Centre of Excellence for Coral Reef Studies, James Cook University, Townsville, QLD 4812, Australia \\ ${ }^{2}$ Department of Natural Science and Public Health, Zayed University, Abu Dhabi, United Arab Emirates \\ ${ }^{3}$ New York University, Abu Dhabi, United Arab Emirates
}

\section{V1 First published: 27 Mar 2014, 3:78 \\ https://doi.org/10.12688/f1000research.3846.1}

Latest published: 09 Apr 2014, 3:78

https://doi.org/10.12688/f1000research.3846.2

\section{Abstract}

Determining when corals reproduce has clear management and economic implications. Here we document the reproductive condition of corals in the genus Acropora on the island of Socotra in Yemen during February 2014. Twenty percent of colonies $(n=143)$ contained mature gametes and $28 \%$ had immature gametes indicating that spawning will occur in both February and March in 2014, confirming previous anecdotal reports of coral spawning at this time in Socotra. Acropora typically reproduce in synchrony with many other broadcast spawning scleractinian corals, and we therefore predict that many other species are reproductively active at this time of year.

Open Peer Review
Approval Status
version 2
(revision)
09 Apr 2014
version 1
27 Mar 2014
1..............................................................................
Hean Kenyon, US Fish and Wildlife Service,
2. Bert W. Hoeksema, Naturalis Biodiversity
Center, Leiden, The Netherlands
Any reports and responses or comments on the
article can be found at the end of the article.

Corresponding author: Andrew H. Baird (andrew.baird@jcu.edu.au)

Competing interests: No competing interests were disclosed.

Grant information: Funding was provided by the Australian Research Council Centre of Excellence for Coral Reef Studies COE561432 (AHB).

The funders had no role in study design, data collection and analysis, decision to publish, or preparation of the manuscript.

Copyright: @ 2014 Baird AH et al. This is an open access article distributed under the terms of the Creative Commons Attribution License , which permits unrestricted use, distribution, and reproduction in any medium, provided the original work is properly cited. Data associated with the article are available under the terms of the Creative Commons Zero "No rights reserved" data waiver (CC0 1.0 Public domain dedication).

How to cite this article: Baird AH, Abrego D, Howells EJ and Cumbo VR. The reproductive season of scleractinian corals in Socotra, Yemen [version 1; peer review: 2 approved] F1000Research 2014, 3:78 https://doi.org/10.12688/f1000research.3846.1

First published: 27 Mar 2014, 3:78 https://doi.org/10.12688/f1000research.3846.1 


\section{Observation}

Most hermatypic scleractinian corals have an annual gametogenic cycle that culminates in the broadcast spawning of gametes once per year ${ }^{1}$. In most reef regions, numerous species spawn in sychrony following full moons when sea surface temperature is either rising or falling ${ }^{2,3}$. Determining exactly when spawning takes place has important implications for reef management and clear economic benefits ${ }^{4}$. For example, activities that are likely to limit fertilization success, such as dredging, can be prohibited during these often brief spawning periods ${ }^{5}$. In addition, the diving industry can benefit from public interest in coral spawning.

Here, we document the reproductive condition of Acropora corals on the island of Socotra, Republic of Yemen. The island, located $240 \mathrm{~km}$ east of the Horn of Africa and $380 \mathrm{~km}$ south of the Arabian Peninsula, supports a diverse scleractinian fauna of over 250 species $^{6}$, and includes sites with a high cover of Acropora (Figure 1). Acropora colonies were sampled before the full moon on 15 February 2014 to determine their reproductive condition. Three reproductive conditions were defined based on the appearance of the oocytes as observed with the naked eye in the field ${ }^{7}$ (1) mature - oocytes pigmented and therefore likely to spawn within a month (2) immature - oocytes pale but visible indicating that they are close to maturity and likely to spawn within two to three months (3) empty - oocytes too small to see or absent indicating either that the colony has recently spawned, or is unlikely to do so for at least three months.

A total of 143 Acropora colonies from approximately 14 species were sampled at four sites on the north of Socotra (Samerhur $12^{\circ} 41^{\prime} 40.96^{\prime \prime} \mathrm{N}, 53^{\circ} 29^{\prime} 3.69^{\prime \prime} \mathrm{E}$; Qaiso $12^{\circ} 39^{\prime} 58.91^{\prime \prime} \mathrm{N}, 53^{\circ} 24^{\prime} 33.86^{\prime \prime} \mathrm{E}$; Dihamri $12^{\circ} 40^{\prime} 20.35^{\prime \prime} \mathrm{N}, 54^{\circ} 11^{\prime} 39.966^{\prime} \mathrm{E}$; Hadibo $12^{\circ} 40^{\prime} 0.77^{\prime \prime} \mathrm{N}$, $\left.54^{\circ} 3^{\prime} 7.74^{\prime \prime} \mathrm{E}\right)$ between the 31 January and 8 February 2014 (Table 1). Twenty percent of colonies contained mature oocytes (Figure 2), $28 \%$ contained immature oocytes and no oocytes were visible in the remaining $52 \%$ of colonies (Table 1). Colonies with mature oocytes are highly likely to spawn at some time around the full moon in February 2014, whereas colonies with immature oocytes are likely to spawn in March 2014. The remaining colonies have either spawned recently, or alternatively, there could be a second reproductive season later in the year, similar to Western Australia $^{8}$, Singapore ${ }^{9}$ and some locations in Indonesia ${ }^{1}$. Ten species had at least one colony with mature gametes (Table 1) suggesting a multi-species spawning event is likely in February 2014. The Acropora typically reproduce at much the same time as most other broadcast spawning scleractinian corals ${ }^{10,11}$ and therefore we predict that many other species will be spawning in February and March in Socotra. Our results confirm previous anecdotal reports of coral spawning on Socotra in February and March ${ }^{6}$. In addition, these data add to a growing body of evidence indicating that

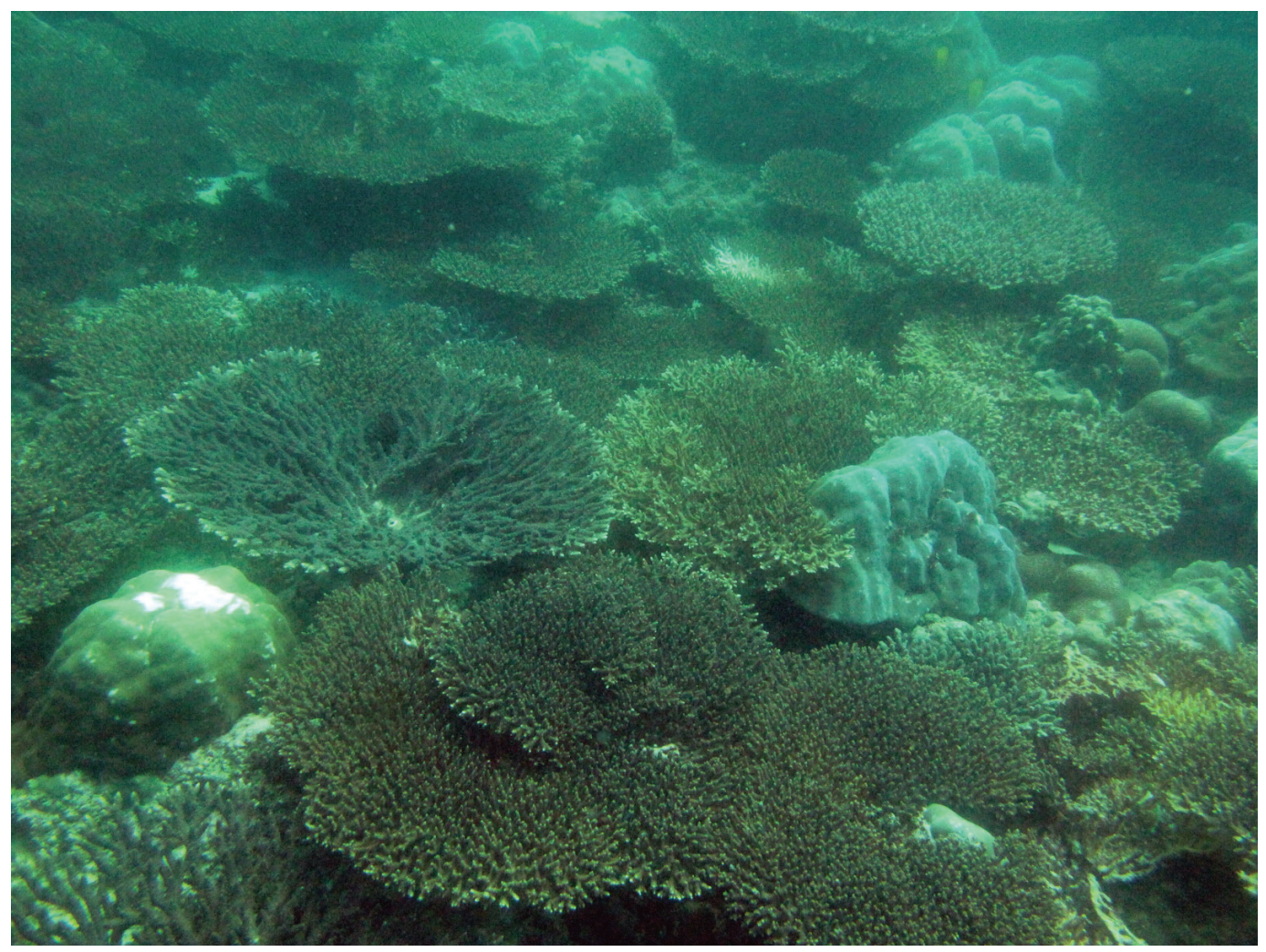

Figure 1. The island of Socotra supports diverse assemblages of Acropora species. 
Table 1. The percentage of Acropora colonies with mature-, immature- or no oocytes, sampled between 31 January and 8 February 2014 on Socotra Yemen. $n=$ number of sampled colonies.

\begin{tabular}{|lllll|}
\hline Species & Percentage mature & Percentage immature & Percentage empty & $\mathbf{n}$ \\
\hline Acropora appressa & 100 & 0 & 0 & 1 \\
\hline Acropora dendrum & 100 & 0 & 0 & 2 \\
\hline Acropora downingi & 0 & 7 & 93 & 14 \\
\hline Acropora cf humilis & 8 & 46 & 46 & 13 \\
\hline Acropora lamarki & 33 & 33 & 33 & 3 \\
\hline Acropora cf lutkeni & 33 & 33 & 33 & 12 \\
\hline Acropora microphthalma & 0 & 0 & 100 & 2 \\
\hline Acropora formosa & 0 & 11 & 89 & 18 \\
\hline Acropora nasuta & 100 & 0 & 0 & 1 \\
\hline Acropora roseni & 0 & 27 & 73 & 11 \\
\hline Acropora cf solitaryensis & 67 & 33 & 0 & 3 \\
\hline Acropora cf spicifera & 21 & 38 & 42 & 48 \\
\hline Acropora valida & 44 & 33 & 22 & 9 \\
\hline Acropora verweyi & 50 & 17 & 33 & 6 \\
\hline Total & 20 & 28 & 52 & 143 \\
\hline
\end{tabular}

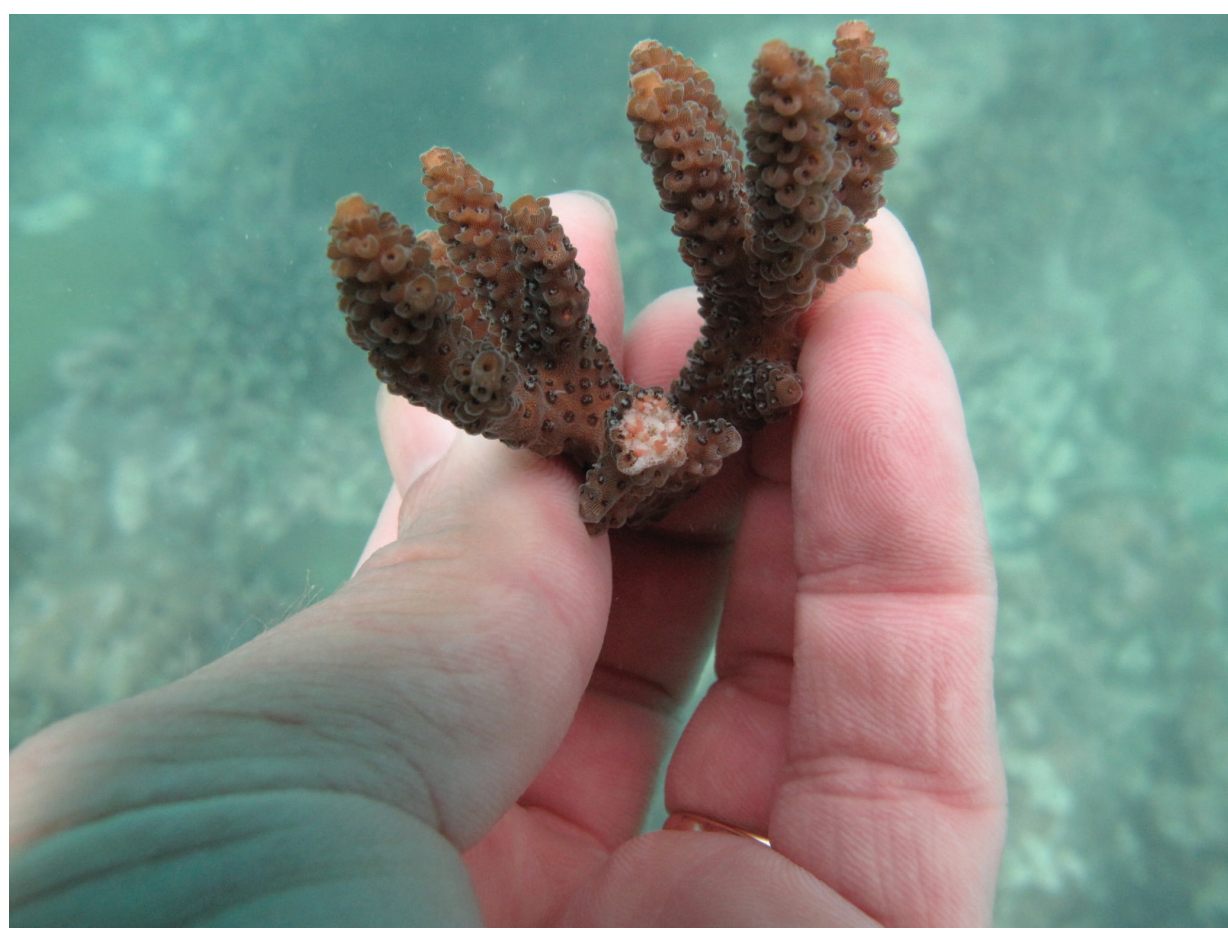

Figure 2. Mature (colored) oocytes are clearly visible in the branches of Acropora colonies. 
multi-specific spawning synchrony is a feature of all speciose coral assemblages ${ }^{1}$.

Author contributions

All authors conceived the study, collected the data and wrote the manuscript.

Competing interests

No competing interests were disclosed.
Grant information

Funding was provided by the Australian Research Council Centre of Excellence for Coral Reef Studies COE561432 (AHB).

The funders had no role in study design, data collection and analysis, decision to publish, or preparation of the manuscript.

\section{Acknowledgements}

We thank Ahmed Eissa Ali Bin Affrar, Ali Yahai and Abdulaziz for logistical support in Socotra.
1. Baird AH, Guest JR, Willis BL: Systematic and biogeographical patterns in the reproductive biology of scleractinian corals. Annu Rev Ecol Evol Syst. 2009; 40: $551-571$

Publisher Full Text

2. Willis $B L$, Babcock $R C$, Harrison $P L$, et al: Patterns in the mass spawning of corals on the Great Barrier Reef from 1981 to 1984. Proc 5th Int Coral Reef Symp. 1985; 4: 343-348.

Reference Source

3. Guest JR, Baird $\mathrm{AH}$, Goh $\mathrm{BPL}$, et al: Seasonal reproduction in equatorial ree corals. Invertebrate Reproduction \& Development. 2005; 48(1-3): 207-218. Publisher Full Text

4. Baird AH, Kospartov MC, Purcell S: Reproductive synchrony in Acropora assemblages on reefs of New Caledonia. Pac Sci. 2010; 64(3): 405-412. Publisher Full Text

5. Baird AH, Blakeway DR, Hurley TJ, et al:: Seasonality of coral reproduction in the Dampier Archipelago, northern Western Australia. Mar Biol. 2011; 158(2): 275-285.

Publisher Full Text

6. DeVantier L, De'Ath G, Klaus R, et al:: Reef-building corals and coral communities of the Socotra Archipelago, a zoogeographic 'crossroads' in the Arabian Sea. Fauna of Arabia. 2004; 20: 117-168.

Reference Source

7. Baird $\mathrm{AH}$, Marshall PA, Wolstenholme $\mathrm{J}$ : Latitudinal variation in the reproduction of Acropora in the Coral Sea. Proc 9th Int Coral Reef Symp. 2002; 1: 385-389. Reference Source

8. Gilmour JP, Smith LD, Brinkman RM: Biannual spawning, rapid larval development and evidence of self-seeding for scleractinian corals at an isolated system of reefs. Mar Biol. 2009; 156: 1297-1309. Publisher Full Text

9. Guest JR, Baird AH, Goh BPL, et al.: Reproductive seasonality in an equatorial assemblage of scleractinian corals. Coral Reefs. 2005; 24(1): 112-116. Publisher Full Text

10. Harrison PL, Babcock RC, Bull GD, et al:: Mass spawning in tropical reef corals. Science. 1984; 223(4641): 1186-1189. PubMed Abstract | Publisher Full Tex

11. Babcock RC, Willis BL, Simpson CJ: Mass spawning of corals on a high latitude coral reef. Coral Reefs. 1994; 13(3): 161-169. Publisher Full Text 


\section{Open Peer Review}

\section{Current Peer Review Status:}

\section{Version 1}

Reviewer Report 01 April 2014

https://doi.org/10.5256/f1000research.4119.r4321

(c) 2014 Hoeksema B. This is an open access peer review report distributed under the terms of the Creative Commons Attribution License, which permits unrestricted use, distribution, and reproduction in any medium, provided the original work is properly cited.

\section{Bert W. Hoeksema}

Department of Marine Zoology, Naturalis Biodiversity Center, Leiden, The Netherlands

This short publication presents clear results and is well written. I have one comment. The conclusive sentence seems redundant, and may need rephrasing or some additional explanation if the authors want to maintain it. "In addition, these data add to a growing body of evidence indicating that multi-specific spawning synchrony is a feature of all speciose coral assemblages."

The present results concern a selection of Acropora species. I wonder whether this would be sufficiently representative for a speciose coral assemblage. In theory any assemblage of two coral species can be considered multi-specific. With many Acropora species in a speciose coral assemblage, some degree of spawning synchrony is not surprising. So, in the present context I wonder if there is a minimum number of species for what counts as speciose and if the authors have a minimum number or percentage in mind for what exactly counts as multi-species spawning. If the authors cannot clarify their remark or cannot give more supportive information to this statement, I suggest that this sentence should be removed.

Competing Interests: No competing interests were disclosed.

I confirm that I have read this submission and believe that I have an appropriate level of expertise to confirm that it is of an acceptable scientific standard.

Author Response ( F1000Research Advisory Board Member ) 08 Apr 2014

Andrew Baird, James Cook University, Townsville, Australia

We have removed the sentence as suggested.

Competing Interests: No competing interests were disclosed. 
Reviewer Report 28 March 2014

https://doi.org/10.5256/f1000research.4119.r4277

(c) 2014 Kenyon J. This is an open access peer review report distributed under the terms of the Creative Commons Attribution License, which permits unrestricted use, distribution, and reproduction in any medium, provided the original work is properly cited.

\section{Jean Kenyon}

Hawaiian and Pacific Islands National Wildlife Refuge Complex, US Fish and Wildlife Service, Honolulu, HI, USA

Background information, purpose of study, data, and interpretation are all clearly and concisely presented. Documentation of coral sexual reproductive status at Socotra, Yemen in 14 species of Acropora provides a useful first contribution to improved understanding of global patterns of this reef maintenance and renewal process. Given that more than 250 species of scleractinian corals are supported at the island, it would be interesting and useful to extend these initial studies to additional species at other times of the year, and to confirm inferred spawning period and synchrony with field observations.

That said, I would suggest that the article title, "The reproductive season of scleractinian corals in Socotra, Yemen" is too broad, given that only $~ 5 \%$ of the scleractinian fauna was sampled. A more focused title should indicate that the observations are confined to the genus Acropora. Within the article, it would also be informative to provide the number of species of Acropora reported among the scleractinian fauna, so as to give some perspective on the proportion of Acropora species sampled.

Competing Interests: No competing interests were disclosed.

\section{I confirm that I have read this submission and believe that I have an appropriate level of} expertise to confirm that it is of an acceptable scientific standard.

Author Response ( F1000Research Advisory Board Member ) 08 Apr 2014

Andrew Baird, James Cook University, Townsville, Australia

We have changed the title to "The reproductive season of Acropora in Socotra, Yemen". We have also provided the number of Acropora species reported to occur in Socotra as listed by Devantier et al., 2004.

Competing Interests: No competing interests were disclosed. 
The benefits of publishing with F1000Research:

- Your article is published within days, with no editorial bias

- You can publish traditional articles, null/negative results, case reports, data notes and more

- The peer review process is transparent and collaborative

- Your article is indexed in PubMed after passing peer review

- Dedicated customer support at every stage

For pre-submission enquiries, contact research@f1000.com 